\title{
ABSENCE OF PALMAR DIGITAL TRIRADIUS $d$ OBSERVED IN 2,681 JAPANESE FAMILIES AND CLINICAL SIGNIFICANCE
}

\author{
Michio OKaJIma ${ }^{1}$ and Chizuko IwaYANaGI ${ }^{2}$ \\ ${ }^{1}$ Department of Forensic Medicine, Tokyo Medical and Dental University, \\ Bunkyo-ku, Tokyo 113, Japan, and \\ ${ }^{2}$ Department of Anthropology, University of Tokyo, \\ Bunkyo-ku, Tokyo 113, Japan
}

\begin{abstract}
Summary The absence of palmar digital triradius d (ADTd), a rare dermatoglyphic trait, was examined in 2,681 Japanese families. The frequency of individuals with this trait was $0.62 \%$, but no sex difference was found. It appears more frequently on the left palm than the right and the bilateral occurrence seems to be more often in familial cases than sporadic ones. It was suggested that the ADRd is transmitted and expressed in a mode of multifactorial inheritance. From the present results and reported cases, the threshold is considered to be shifted by various developmental conditions such as congenital anomalies, familial occurrence and, possibly, twinning.
\end{abstract}

\section{INTRODUCTION}

The absence of palmar digital triradius $\mathrm{d}$ (ADTd) is a rare dermatoglyphic trait, especially so in whites (Cummins and Midlo, 1961; David, 1978; Sharma, 1979; Rosa, 1979; Gupta et al., 1984), but it appears somewhat more frequently in the Japanese (Kasai, 1951a, b; Okajima et al., 1982). As the genetic analysis of such a rare characteristic requires a large number of familial samples, the genetic features of this trait have remained unclarified, except for few familial occurrences (Holt and Sharma, 1977; Abdullah, 1979; Wertelecki et al., 1980). However, some genetic and environmental influences on the expression have been suggested by a study on twins and their parents (Okajima et al., 1982).

In this report, we have examined the occurrence of ADTd in 2,681 Japanese families from the genetic viewpoint. 


\section{MATERIALS AND METHODS}

The subjects of this study were palm prints from 2,681 Japanese families composed of both parents and one or more children. These samples were collected by the late Prof. T. Furuhata in the 1930's and are now in the possession of the Department of Forensic Medicine of the Tokyo Medical and Dental University. The subjects comprise 5,986 males, including 2,681 fathers and 3,305 sons, and 5,533 females, including 2,681 mothers and 2,852 daughters. The materials used in this study also include palm prints of 2,500 individuals that were reported by Kasai (1951a, b).

The ADTd was classified by the same criteria as in the previous paper (Okajima et al., 1982).

\section{RESULTS}

\section{Frequency of $A D T d$}

The frequency of the ADTd is shown in Table 1. The number of individuals with ADTd on one or both palms is $37(0.62 \%)$ for males and $34(0.61 \%)$ for females, with no sex difference being found $(p>0.95)$.

The occurrence of ADTd on the left palm, 34 for males and 30 females, is significantly higher than the right, eight and nine, respectively $(p<0.001)$.

\section{Comparison of frequencies between the present and twin materials}

The occurrence of ADTd was compared between the present study and the twins and their parents in the previous report (Okajima et al., 1982) (Table 2). The frequency in the twins, $21 / 2,020(1.04 \%)$, is higher than that in the present subjects, $71 / 11,519(0.62 \%)$, at the significantly level $\left(\chi^{2}=4.56,0.05>p>0.02\right)$. However,

Table 1. Frequency of absent digital triradius d (ADTd) in 2,681 Japanese families.

\begin{tabular}{lccccc}
\hline & \multicolumn{4}{c}{ Absence of triradius d } & \\
Left hand & & Right hand & Both hands & None & Total \\
Fathers & 16 & 0 & 2 & 2,663 & 2,681 \\
Sons & 13 & 3 & 3 & 3,286 & 3,305 \\
Total & 29 & 3 & 5 & 5,949 & 5,986 \\
$\%$ & 0.49 & 0.05 & 0.08 & 99.38 & 100.00 \\
Mothers & 13 & 1 & 5 & 2,662 & 2,681 \\
Daughters & 12 & 3 & 0 & 2,837 & 2,852 \\
Total & 25 & 4 & 5 & 5,499 & 5,533 \\
$\%$ & 0.45 & 0.07 & 0.09 & 99.39 & 100.00 \\
\hline
\end{tabular}


Table 2. Comparison of frequencies of ADTd from different groups.

\begin{tabular}{|c|c|c|c|c|c|c|}
\hline & \multicolumn{2}{|c|}{$d(++)^{b}$} & \multicolumn{2}{|c|}{$\mathrm{d}(-)^{\mathrm{c}}$} & \multicolumn{2}{|c|}{ Total } \\
\hline & No. & $\%$ & No. & $\%$ & No. & $\%$ \\
\hline Present study & 11,448 & 99.38 & 71 & 0.62 & 11,519 & 100.00 \\
\hline Twins $^{\mathrm{a}}$ & 1,999 & 98.96 & 21 & 1.04 & 2,020 & 100.00 \\
\hline Parents of twins ${ }^{a}$ & 829 & 99.16 & 7 & 0.84 & 836 & 100.00 \\
\hline
\end{tabular}

a Okajima et al., 1982. b $(+)$, ADTd is present on both palms; ${ }^{\mathrm{c}}(-)$, ADTd is absent on one or both palms.

Table 3. Number of families according to mating type of parents and number of siblings with ADTd.

\begin{tabular}{|c|c|c|c|c|c|c|c|c|c|c|c|}
\hline \multirow{3}{*}{ No. of siblings } & \multicolumn{5}{|c|}{$d(+) \times d(+)$} & \multicolumn{4}{|c|}{$d(+) \times d(-)$} & \multicolumn{2}{|c|}{$\mathrm{d}(-) \times \mathrm{d}(-)$} \\
\hline & \multicolumn{5}{|c|}{ Siblings with ADTd } & \multicolumn{4}{|c|}{ Siblings with ADTd } & \multirow{2}{*}{\multicolumn{2}{|c|}{ Total }} \\
\hline & 0 & 1 & 2 & $\begin{array}{l}3 \text { or } \\
\text { more }\end{array}$ & Total & 0 & 1 & $\begin{array}{l}2 \text { or } \\
\text { more }\end{array}$ & Total & & \\
\hline 1 & 752 & 6 & & & 758 & 9 & & & 9 & & 767 \\
\hline 2 & 935 & 9 & 1 & & 945 & 13 & 1 & & 14 & & 959 \\
\hline 3 & 543 & 7 & & & 550 & 10 & & & 10 & & 560 \\
\hline 4 & 248 & 3 & 1 & & 252 & 1 & & & 1 & & 253 \\
\hline 5 & 94 & 3 & & & 97 & 1 & 1 & & 2 & & 99 \\
\hline 6 & 25 & & & & 25 & 1 & & & 1 & & 26 \\
\hline 7 & 14 & & & & 14 & & & & & & 14 \\
\hline 8 & 2 & & & & 2 & & & & & & 2 \\
\hline 9 & 1 & & & & 1 & & & & & & 1 \\
\hline $\begin{array}{l}\text { Total No. } \\
\text { of families }\end{array}$ & 2,614 & 28 & 2 & 0 & 2,644 & 35 & 2 & 0 & 37 & 0 & 2,681 \\
\hline $\begin{array}{l}\text { Total No. } \\
\text { of children }\end{array}$ & 5,986 & 72 & 6 & 0 & 6,064 & 80 & 7 & 0 & 87 & 0 & 6,151 \\
\hline
\end{tabular}

the frequency of the parents of twins, $7 / 836(0.84 \%)$, is intermediate between the present subjects and the twins, and not significantly different from either group $\left(\chi^{2}=0.61, p>0.30 ; \chi^{2}=0.25, p>0.50\right)$. Therefore, further observations are needed to conclude that the increase of ADTd is associated with the mechanism of twinning.

\section{Occurrence of ADTd in families}

The combination of parents with and without the ADTd and the segregation in the children are presented in Table 3, both sexes pooled, as no sex difference was observed. 
Among 6,064 children from 2,644 families in which neither parents had ADTd, the absence was found in 32 children from 30 families, two each of them being sibs in two families. In 87 children from 37 families in which one parent presented ADTd, the absence was found in two children from two families. There were no families in which both parents had ADTd.

\section{Bilateral occurrence of $A D T d$}

Among 71 individuals with ADTd, including both parents and children, 63 were single occurrence and eight were familial. The latter comprises two parent-child combinations, i.e., father and son and mother and son, and two pairs of sibs, i.e., two brothers and two sisters. Among these eight familial cases, two showed bilateral occurrence, i.e., one mother and one son from different families. The bilateral occurrence in the familial cases, $2 / 8(25 \%)$, is higher than the single cases, $8 / 63(13 \%)$.

In the twin materials reported by the present author (Okajima et al., 1982), bilateral occurrence was observed in two among 28 cases with ADTd. One of the two cases was a monozygotic twin and the co-twin presented ADTd on the left palm. The other case was a dizytotic twin, but the co-twin did not possess ADTd on both palms and the parents were not examined.

\section{DISCUSSION}

As previously reported in Japanese twins and their families (Okajima et al., 1982), it was demonstrated by monozygotic twins that the penetrance of the ADTd is very low. When the present and previous data are combined (Table 4), the frequency of ADTd in the children from the parents of which one also presented the ADTd is $4 / 101(3.96 \%)$ and higher than that from the parents in which none had the ADTd, $41 / 6,886(0.60 \%)$, at the significant level $\left(\chi^{2}=12.74\right.$ after Yates' correction, $p<0.001$ ). This indicates a genetic influence on the appearance of the ADTd.

However, the low recurrence ratio in the children does not support the mode of dominant inheritance with a relatively high penetrance. Then, the mode of auto-

Table 4. Occurrence of ADTd in children from different combinations of parents. Data from the present study and 418 twin families (Okajima et al., 1982) are combined.

\begin{tabular}{lrrrr}
\hline $\begin{array}{c}\text { Combination } \\
\text { of parents }\end{array}$ & $\begin{array}{c}\text { Number of } \\
\text { families }\end{array}$ & \multicolumn{2}{c}{ Children } & Total \\
\hline $\mathrm{d}(+) \times \mathrm{d}(+)$ & 3,055 & $6,845(99.40 \%)$ & $41(0.60 \%)$ & $6,886(100.00 \%)$ \\
$\mathrm{d}(+) \times \mathrm{d}(-)$ & 44 & $97(96.23 \%)$ & $4(3.77 \%)$ & $101(100.00 \%)$ \\
$\mathrm{d}(-) \times \mathrm{d}(-)$ & 0 & 0 & 0 & 0 \\
Total & 3,099 & $6,942(99.36 \%)$ & $45(0.64 \%)$ & $6,987(100.00 \%)$ \\
\hline
\end{tabular}


somal recessive inheritance was examined by applying the Weinberg's proband method. From Table 3, offspring were pooled from families in which both parents did not possess ADTd but at least one child had this trait. The occurrence of ADTd in offspring other than probands is $2 / 48=0.02$. This is much smaller than the expected value, 0.25 . Therefore, the inheritance by a recessive gene is negligible. These results suggest that the trait is transmitted in a mode of multifactorial inheritance as other dermatoglyphic characteristics (Katayama, 1980, 1981).

Absent triradius $\mathbf{d}$ is occasionally observed in various kinds of congenital disorders. For example, it was reported in three children of a family with hand malformation of syndactyly type V (Robinow et al., 1982), three of 800 patients with congenital heart disease (CHD) (David, 1978), a case of 4q trisomy (Yoshida et al., 1978), a case of abnormality of chromosome 15 (Kelly et al., 1969), two cases of 49, XXXXY constitution, three cases of other miscellaneous disorders (David, 1978), and two of 12 Kabuki make-up syndrome patients (Niikawa et al., 1982). Thus the occurrence is sporadic and the pathognomonic criteria have not yet been established. However, the fact that among these reported cases, the bilateral expression was observed in three syndactyly patients, one case of familial CHD, two cases of autosomal chromosome anomalies, one case of $49, \mathrm{XXXXY}$ and one of Kabuki make-up syndrome patients, suggests a relatively higher occurrence in congenital anomalies than in normal populations.

From these clinical findings in reported cases and the present data, the threshold concerned to the expression of ADTd as well as the bilateral occurrence is considered to be shifted by various developmental conditions such as congenital anomalies, familial occurrence and, possibly, in twinning.

\section{REFERENCES}

Abdullah, N.F. 1979. Inheritance of palmar triradii suppression. Birth Defects: Orig. Art. Ser. 15(6), 529-538.

Cummins, H. and Midlo, C. 1961. Finger Prints, Palms and Soles. Dover Publ., New York, p. 111.

David, T.J. 1978. Absence of the d triradius. Ann. Hum. Genet. 42, 193-196.

Gupta, C.M., Tutakne, M.A., and Bhanu, B.V. 1984. Absence of triradius d on the palm of a leprosy patient. Ind. J. Leprosy 56, 852-854.

Holt, S.B. and Sharma, P.D. 1977. Absence of triradius d on the palms of normal people. Ann. Hum. Genet. 41, 195-197.

Kasai, K. 1951a. Report on the investigation of palmar patterns in 2500 Japanese. Jpn. J. Legal Med. (in Japanese) 5, 140-146.

Kasai, K. 1951b. Frequency of main line in Japanese, classified by Wilder and revised method by Cummins-Midlo. Jpn. J. Legal Med. (in Japanese) 5, 147-154.

Katayama, K. 1980. Genetic study of missing c triradius on the palm: estimation of the heritability of liability. Jpn. J. Hum. Genet. 25, 23-27.

Katayama, K. 1981. Genetic study of hypothenar patterns on the palm: estimation of the heritability of liability. Jpn. J. Hum. Genet. 26, 279-288.

Kelly, S., Almy, R., and Dagle, A. 1969. Chromosome 15 abnormality in a mentally retarded adult. J. Med. Genet. 6, 438-441. 
Niikawa, N., Kuroki, Y., and Kajii, T. 1982. The dermatoglyphic pattern of the Kabuki make-up syndrome. Clin. Genet. 21, 315-320.

Okajima, M., Iwayanagi, C., and Inouye, E. 1982. Absence of palmar digital triradius d in Japanese twins and their families. Jpn. J. Hum. Genet. 27, 27-34.

Robinow, M., Johnson, G.F., and Broock, G.J. 1982. Syndactyly type V. Am. J. Med. Genet. 11, 475-482.

Rosa, P.J. 1979. Absence of palmar triradius d in a series of Kenyan samples. Ann. Hum. Biol. $6,269-278$.

Sharma, P.D. 1979. Further observations on absence of palmar triradius d in normal people. $\mathrm{Am}$. J. Phys. Anthropol. 50, 213.

Wertelecki, W., Plato, C., and Plato, C.C. 1980. Absent d triradius and dotting of the ridges in siblings. Hum. Hered. 30, 368-371.

Yoshida, Y., Fujita, H., and Hase, Y. 1978. Partial trisomy $4 \mathrm{q}$ resulting from a $\mathrm{t}(4 \mathrm{q}: 10 \mathrm{q})$ reciprocal translocation. Shonika-Shinryo (in Japanese) 41, 1523-1526. 